\title{
As indenizações como política de direitos humanos e de justiça social no Brasil contemporâneo'
}

\author{
Indemnities as a human right and social justice policy in \\ contemporary Brazil
}

\section{Paula Lacerda}

Brasil. Universidade do Estado do Rio de Janeiro. Professora Adjunta do Departamento de Antropologia e do Programa de Pós-Graduação em Ciências Sociais da Universidade do Estado do Rio de Janeiro. Possui graduação em Ciências Sociais pela Universidade do Estado do Rio de Janeiro (2004), mestrado em Saúde Coletiva pelo Instituto de Medicina Social da Universidade do Estado do Rio de Janeiro (2006), doutorado pelo Programa de Pós-Graduação em Antropologia Social do Museu Nacional da Universidade Federal do Rio de Janeiro (2012) e pós-doutorado no Programa de Pós-Graduação em Antropologia Social do Museu Nacional da Universidade Federal do Rio de Janeiro (2013) e na Universidade Nacional de Córdoba (2019). ID ORCID: http://orcid.org/oooo0003-2938-8136. E-mail: lacerdapaula@gmail.com.

\section{Resumo}

Este artigo propõe analisar as indenizações: práticas recorrentes no campo contemporâneo dos direitos humanos que implicam no pagamento de uma quantia em dinheiro em situações de violações de direitos. Para a presente análise, foram selecionados "casos" de violação de direitos em que a indenização colocou em interação sujeitos que se apresentam como "familiares de vítimas" e gestores públicos representantes do "Estado" - ainda que as violações não tenham sido cometidas, necessariamente, por agentes públicos. Ao compreender as práticas de compensação econômica no cenário mais amplo das políticas de reparação,

Esse artigo é fruto de financiamento da Coordenação de Aperfeiçoamento de Pessoal de Nível Superior (Capes), por meio do Edital Memórias Brasileiras/Conflitos, do Conselho Nacional de Pesquisa Científica (CNPq), por meio da chamada MCTI/CNPQ/MEC/Capes nº 22/2014, e da Fundação Carlos Chagas Filho de Amparo à Pesquisa do Estado do Rio de Janeiro (Faperj) e do Programa de Bolsas de Iniciação Científica (Pibic) da Universidade do Estado do Rio de Janeiro (UERJ), por meio de bolsas de Iniciação Científica. A pesquisa que deu origem ao artigo é projeto participante do Programa de Incentivo à Produção Científica, Técnica e Artística (Prociencia), da UERJ.

Recebido em 25 de julho de 2019 Avaliador A: 10 de agosto de 2019

Avaliador B: 27 de agosto de 2019

Aceito em 27 de agosto de 2019 
pôde-se observar que as indenizações são práticas ambivalentes que - apesar de convergirem com os anseios dos sujeitos violados e até mesmo de organismos internacionais de relevância no cenário dos direitos humanos - podem ser instrumentalizadas de forma dissociativa e não comprometida com a promoção da justiça e da reparação.

Palavras-chave: Políticas de Reparação, Indenizações, Direitos Humanos, Estado.

\section{Abstract}

This article analyzes compensations, current ordinary practices in the human rights field implying the payment of a sum of money as a compensation for the violation of rights. Cases concerning the violation of rights in which the practice of indemnity made subjects self-described as relatives of the victims interact with each other and public managers representing the State were analyzed, in addition to situations in which such violations were not necessarily committed by public agents. When considering economic compensation practices in the broader context of reparation policies in Brazil, it was observed that indemnities are an ambivalent practice. Although often understood as a desirable legal answer by subjects whose rights have been violated and presented as an effective action by relevant international organizations at the field of human rights, it can also be applied in a dissociative manner not committed to the promotion of justice and reparation.

Keywords: Reparation Policies, Indemnity, Human Rights, State.

\section{INTRODUÇÃO}

Em abril de 2019, alcançou grande repercussão a notícia de que o governo do estado de São Paulo indenizaria as famílias das vítimas e os/as sobreviventes do massacre ocorrido na escola pública Raul Brasil, em Suzano, região metropolitana. O "caso" , ocorrido em 13 de março desse mesmo ano, consistiu no assassinato de

2 Utilizo "caso" entre aspas para enfatizar a dimensão de um acontecimento político com versões discordantes, seguindo autores de tradição francesa como Boltanski, Darré e Schlitz (1984) e Claverie (1998). 
oito pessoas, sendo cinco estudantes, duas funcionárias da escola e um comerciante, foi cometido por dois jovens, de 17 e de 25 anos, que entraram na escola com revólver, machado, equipamento de arco e flecha, bombas caseiras, entre outros armamentos, e se mataram logo após. Segundo reportagens da época, esse teria sido o oitavo ataque a escolas no Brasil (BASILIO, 2019; REALENGO..., 2019). O governador de São Paulo, João Dória, compareceu à escola no mesmo dia do massacre, acompanhado de autoridades da Secretaria de Educação, da Secretaria de Segurança Pública e da Polícia Militar (PM).

A repercussão em torno da notícia da indenização a ser paga se explica (LOURENÇO, 2019), principalmente, por dois fatores: (i) a celeridade com que o processo de indenização tramitou e (ii) a impossibilidade de qualquer ato processual posterior relacionado à demanda por indenizações. No que se refere à rápida tramitação da indenização, no dia seguinte ao crime foi publicado o Decreto 64.145/19 (SÃO PAULO, 15 mar.2019) autorizando pagamento às vítimas e instituindo Comissão Executiva para elaborar os critérios e demais aspectos das indenizações. A publicação desse decreto possibilitou que as indenizações fossem pagas em menos de 90 dias após o crime, o que foi considerado um marco pela Procuradoria Geral do Estado. O segundo fator foi a cláusula constante nas diretrizes da Comissão Executiva formada por efeito dos atos do decreto anteriormente citado, que estipula a "quitação de todos os débitos decorrentes do dever do Estado de indenização em relação ao evento" (SÃO PAULO, 6 abr. 2019, p. 146). Na explicação de Juliana Belloque, a $1^{a}$ subdefensora pública geral, essa cláusula se justifica porque “[receber as indenizações] é um procedimento voluntário. As famílias, aderindo a esse acordo [...] dão quitação ao dever do Estado de indenizar [...]. Não serão aceitas ações questionando a [...] questão no futuro" (LOURENÇO, 2019, s/p).

\footnotetext{
Analisando o cenário político contemporâneo da França, Boltanski, Darré e Schlitz(1984) afirmam que a forma "caso" (affaire) torna-se linguagem política para a denúncia pública de situações percebidas como injustas. Embora construída a partir de um acontecimento pontual, a forma "caso" é capaz de alcançar escuta e repercussão quando se percebe que a "causa" que apresenta, a despeito de suas configurações singulares, representa ou pode ser relacionada a um maior número de pessoas. Para Claverie (1998), a forma "caso" enquanto formato político tem origem jurídica e se constitui a partir de um desacordo entre as "partes". É interessante notar que, tanto os casos utilizados na análise dessa autora (os conhecidos casos "Cala" e "Dreyfus"), quanto os casos aqui analisados, tratam-se de situações de "violação" em que determinados direitos já se encontravam consagrados em instrumentos legais.
} 
No Brasil, não existem dados relacionadas à concessão de indenizações, sendo desconhecidas as quantidades de pessoas indenizadas ou recursos mobilizados. Da mesma maneira, não existe um caminho único de tramitação das indenizações, podendo ser extrajudicial (via decretos, como no caso da escola Raul Brasil), ou judicial, que por sua vez pode resultar de ações de responsabilidade civil do Estado impetradas junto ao judiciário brasileiro ou também a partir de condenações ou soluções amistosas do Brasil na esfera internacional, em geral arbitradas pela Corte Interamericana de Direitos Humanos. As indenizações judiciais podem tramitar desde a primeira até a instância máxima do judiciário brasileiro, o Superior Tribunal de Justiça (STJ). As instituições públicas implicadas na negociação e na autorização do pagamento de indenizações, de maneira geral, são os órgãos federais e/ou estaduais que atuam nas pastas de direitos humanos, assistência social, desenvolvimento social e cidadania, contando ainda com a atuação da Procuradoria Geral do Estado ou da República.

As indenizações deferidas às vítimas da ditadura brasileira são exceção nesse cenário de falta de informações sistematizadas e de ações públicas unificadas e, como se verá adiante, fazem parte da genealogia das indenizações associadas aos direitos humanos. Nesse âmbito, existem dados bastante precisos e que podem ser obtidos com relativa facilidade no site da Comissão de Anistia, órgão atualmente vinculado ao Ministério da Mulher, Família e Direitos Humanos, que recebe e avalia os pedidos de indenização, além de sistematizar e disponibilizar os dados de sua atuação. Assim, são públicos os dados pessoais de cada uma das vítimas indenizadas, bem como o valor pago pelo Estado brasileiro e a modalidade (mensalidade ou parcela única). As medidas de cálculo desse tipo de indenização também são públicas, o que não quer dizer que não existam conflitos no processo de concessão dessas indenizações bem como questionamentos sobre sua legitimidade e equanimidade. A decisão de indenizar as vítimas da "repressão política" representa um marco na discussão sobre políticas de reparação, e por isso voltaremos a esse tema mais adiante. Por ora, gostaria de enfatizar a pluralidade de caminhos que resultam nas indenizações no Brasil atual e a diversidade de situações possíveis de serem indenizadas, em que pese a falta de dados e reflexões sobre o tema. 
A discussão aqui apresentada é resultado de quatro anos de investigação sobre o tema das indenizações no Brasil pós-1988, cujo objetivo principal é compreender as indenizações como prática efetivada por setores da administração pública ${ }^{3}$ em que há perspectivas aparentemente contraditórias, relativas às violências, dores e sofrimentos percebidos como inesquecíveis e irreparáveis e, por outro lado, à própria possibilidade de reparação de direitos violados, numa modalidade muito específica que é o pagamento de uma quantia em dinheiro. Do cenário amplo e diverso das indenizações -de maneira nenhuma restringe-se ao campo dos direitos humanos, englobando questões trabalhistas, securitárias etc. -, que envolvem tanto órgãos públicos quanto privados, optei por trabalhar apenas com o as situações em que o "Estado" é apontado como o perpetrador ou corresponsável pelas situações consideradas "violações de direitos", seja na fala de vítimas e/ou seus representantes, seja em documentos produzidos pelas burocracias nacionais ou internacionais, seja ainda na fala de gestores/ representantes de órgãos públicos. Argumento, a partir dos dados da pesquisa, que as indenizações, apresentadas como parte de um conjunto mais amplo de medidas de reparação, vem sendo significadas como práticas de direitos humanos e de justiça social mesmo quando dissociadas dessas ações mais abrangentes e comprometidas com a não repetição da violação. Ainda assim, as indenizações convergem com os anseios dos sujeitos violados, pois incidem sobre o reconhecimento da violação sofrida e, também, da identidade de vítima.

Desse artigo, fica de fora uma dimensão importante do cenário das indenizações no Brasil contemporâneo: as indenizações praticadas no âmbito de projetos de desenvolvimento, medidas que compõe as chamadas práticas de mitigação dos planos de grandes empreendimentos no país. Analisando o histórico de construção de barragens no Brasil e tomando como "caso" a usina

\footnotetext{
Faço a opção pela categoria "setores da administração pública" como forma de evitar generalizações e homogeneidades que poderiam ser supostas diante do uso da categoria "Estado". Acompanho, nesse sentido, as formulações de Souza Lima (2002) e Teixeira e Souza Lima (2010) que utilizam os termos gestão e administração para enfatizar a combinação de crença e materialidade presente não só nas esferas da administração direta (nos três níveis da federação), como também o jogo político-partidário, o campo do direito, instituições internacionais etc. Contudo, como se verá, a categoria "Estado" aparecerá (sempre entre aspas) como categoria êmica constante na fala dos interlocutores ou em documentos acessados pela pesquisa.
} 
hidrelétrica de Belo Monte 4 , constatei que é possível observar como as indenizações, nesse âmbito, figuram-se cada vez mais em políticas sociais, se afastando das medidas de indenização inicialmente propostas em projetos hidroelétricos implementados na década de 1970 - que tinham como categoria operante "atingidos" e como unidade de mensuração das indenizações a "propriedade".

Até o momento, foram realizadas 18 entrevistas com vítimas e/ou seus familiares e 6 entrevistas com integrantes de organizações governamentais com atuação no campo dos direitos humanos e expertos em processos de demanda por indenizações. Resta para a próxima etapa da pesquisa a realização de entrevistas com gestores públicos. Entre 2014 e 2018, realizei ou supervisionei trabalho de campo em eventos de direitos humanos ocorridos na cidade do Rio de Janeiro, direta ou indiretamente relacionados ao tema das indenizações ${ }^{6}$. Foram também levantados casos de indenização em (i) portais de notícias da grande imprensa, instituições de direitos humanos, e em perfis e páginas da imprensa alternativa, visando conhecer o cenário geral das indenizações no Brasil contemporâneo; (ii) sites de órgãos do judiciário de segunda (como o Tribunal de Justiça do Estado do Rio de Janeiro) e de terceira instância (Superior Tribunal de Justiça); (iii) no portal da Comissão Interamericana de Direitos Humanos.

Para este artigo, selecionei seis "casos" em que indenizações foram apresentadas como uma possibilidade de reparação à violação de uma série

\footnotetext{
4 A Usina Hidroelétrica de Belo Monte foi construída no rio Xingu, estado do Pará, e afetou diretamente cinco municípios, sendo Altamira o maior e mais populoso deles. Trata-se da maior obra do Programa de Aceleração do Crescimento (PAC), em que foram empregados mais de 26 bilhões de reais. O projeto, elaborado durante os governos militares, quando então se denominava Kararâ - voltou a ser discutido por volta de 2009, com o nome de Belo Monte. O licenciamento do empreendimento, como também as fases posteriores, foram paralisadas inúmeras vezes por determinação de órgãos como o Ministério Público Federal e o Tribunal Regional Federal. Movimentos sociais nacionais e internacionais realizaram inúmeras denúncias sobre as ilegalidades dos procedimentos técnico-administrativos, principalmente no tocante à consulta popular. Pesquisas acadêmicas detalharam as ilegalidades cometidas nesse processo e analisaram como isso foi possível. Ver, entre outros: Reis (2015), Vieira (2015), Vilaça (2017) e Lacerda (2017).

5 Os trabalhos de Sigaud $(1986,1995)$ sobre as hidroelétricas de Sobradinho e Machadinho são fontes de pesquisa e inspiração teórica para a discussão acerca de projetos hidroelétricos e seus "efeitos sociais", categoria empregada pela autora.

6 As bolsistas Letícia Tury (Faperj) e Hyldalice de Andrade (Pibic-Uerj) realizaram, sob supervisão, trabalho de campo em 15 eventos, promovidos por organizações não-governamentais, institutos de pesquisa e setores do governo do estado. Agradeço ao empenho e parceria de ambas.
} 
de direitos, incluindo o direito à vida, por representantes de setores da administração pública, por integrantes de organizações não-governamentais relacionadas aos direitos humanos ou por familiares das vítimas. Em que pese a semelhança dos "casos" aqui trabalhados nessa dimensão fundamental de serem violações de direitos compreendidas como passíveis de restituição monetária, os "casos" são heterogêneos em outras dimensões. A mais importante delas é, justamente, que as indenizações resultam de processos políticos distintos. Como na situação da escola Raul Brasil, há "casos" em que as indenizações são medidas propostas por setores da administração pública, mas há "casos" em que as indenizações são pleiteadas por vítimas e/ou familiares de vítimas, assistidos por instituições atuantes no campo dos direitos humanos - demorando décadas até serem, finalmente, acordadas e concedidas. Em alguns desses eventos, as indenizações fazem parte de um conjunto de medidas apresentadas por cortes internacionais de direitos humanos que, embora não possuam poder punitivo, têm suas decisões respaldadas nos acordos livremente estabelecidos entre países que reafirmam seu compromisso com a democracia e a garantia de direitos. Outra dimensão importante a ser destacada é que, embora nem todas as violações de direito tenham sido cometidas por agentes de órgãos e/ou setores públicos, o "Estado" é considerado agente decisivo nas violações de direito, seja por ação ou omissão, motivo pelo qual as indenizações são demandadas junto aos órgãos em dimensão estadual ou federal, ou diretamente propostas pelos representantes do poder executivo.

Além disso, os "casos" aqui trabalhados são heterogêneos em aspectos menos fundamentais, porém não irrelevantes, como o fato de terem ocorrido em espaços diferentes - como escolas de periferia, favelas, maternidades públicas, interior da Amazônia - ainda que todos eles sejam referidos, pelos agentes envolvidos, como lugares precários, desassistidos e potencialmente cenário de outras vulnerabilidades e violações. Há também "casos” que são referidos por indexadores específicos, indicadores potentes da excepcionalidade da violência e da violação envolvidas: massacre, como o da escola Raul Brasil e chacina, como a ocorrida na favela da Nova Brasília, no Rio de Janeiro. Esse último, como os outros que serão utilizados na análise, serão descritos na sequência. 
Entre 1989 e 1993, na cidade de Altamira, interior do estado do Pará, na Amazônia brasileira, cerca de 24 meninos foram abordados por um estranho em partes movimentadas da cidade, sob a promessa de um trabalho, de uma brincadeira ou de uma comida, levados para locais ermos, como matas e terrenos baldios, onde eram então sedados, amarrados e lesionados em várias partes do corpo, inclusive na genitália. Por essa característica, esse conjunto de crimes que envolveu violência sexual, lesão corporal, homicídio (tentado ou consumado) ficou conhecido como "caso dos meninos emasculados de Altamira", tendo recebido a atenção das organizações sociais locais, regionais, nacionais e até internacionais. $\mathrm{O}$ único processo judicial instaurado apurou crimes contra apenas cinco vítimas, tendo ido a julgamento somente em 2005. Após o que os familiares das vítimas e alguns de seus apoiadores entenderam como o encerramento da "etapa penal" do "caso", foi dada entrada em um processo de indenização, referido como "fase cível”. Em 2008, sob a gestão da governadora Ana Júlia Carepa, do Partido dos Trabalhadores (PT), foi concedida pensão indenizatória para dez familiares das vítimas, no valor de um salário mínimo7.

Também na década de 90, na favela Nova Brasília, no Rio de Janeiro, ocorreram duas chacinas, no intervalo de tempo de seis meses entre outubro de 1994 e abril de 1995. Na primeira data, mais de 100 policiais civis de grupos especializados, invadiram a favela atirando. Como saldo da operação, 13 rapazes foram assassinados e 3 mulheres, sendo duas menores de idade, foram vítimas de violência sexual. Na segunda data, 14 policiais civis invadiram novamente a favela e mataram outros 13 jovens. Apesar da enorme repercussão, as investigações da chacina não apresentaram resultados, motivo pelo qual o "caso" tornou-se objeto de denúncia internacional apresentada pelo Instituto Superior de Estudos da Religião (Iser) e pelo Centro pela Justiça e Direito Internacional (Cejil). Em 2018, a Corte Interamericana de Direitos Humanos condenou o "Estado brasileiro" a indenizar os familiares das vítimas e as vítimas sobreviventes, entre outras medidas consideradas de reparação. Até o momento, as informações disponíveis apontam que nenhuma medida foi cumprida ${ }^{8}$.

\footnotetext{
Ver Lacerda $(2012,2014)$ para descrição detalhada e análise do "caso" em seus múltiplos efeitos.

8 Para mais informações sobre a chacina e medidas de reparação, consultar Souza (2018).
} 
Outro "caso" a ser tratado refere-se à morte materna de Alyne Pimentel, jovem negra de 28 anos, casada e mãe de uma filha, grávida de seis meses quando foi vítima de atendimento médico negligente. No dia 11 de novembro de 2002, Alyne sentia náuseas e fortes dores abdominais quando procurou atendimento em uma unidade local do serviço público de saúde no município de Belford Roxo, região metropolitana do Rio de Janeiro. $\mathrm{O}$ atendimento recebido resultou na prescrição de analgésicos e liberação para retornar para sua casa. Como as dores e o mal-estar persistiam, Alyne retornou à unidade de saúde, quando então foi constatada a morte do seu bebê e, apenas depois de muitas horas de espera, ela foi submetida a uma cirurgia que resultou em complicações. Em vista da gravidade de seu estado de saúde, foi necessário transferi-la para um hospital com mais recursos, mas o procedimento foi realizado com grande atraso. Cinco dias depois de ter dado entrada no hospital com náuseas e dores, Alyne faleceu. A causa de sua morte foi definida como hemorragia pós-parto. No ano seguinte, a morte de Alyne, compreendida como violação do direito à vida promovida pelo estado do Rio de Janeiro e pela prefeitura de Belford Roxo, foi denunciada ao poder judiciário, mas não houve acolhimento da denúncia. Em 2007, a mãe de Alyne, assessorada pelas organizações não-governamentais Center of Reprodutive Health e Advocacia Cidadã pelos Direitos Humanos denunciaram esse conjunto de violações ao Comitê para a Eliminação de Todas as Formas de Discriminação contra a Mulher (Cedaw), tendo resultado, quatro anos depois, na responsabilização do Estado brasileiro e na determinação de pagamento de indenização à mãe da vítima, entre outras medidas. O "caso" e seus desdobramentos, que representam um marco por se tratar do primeiro episódio de responsabilização de um governo por morte materna evitável por parte de um órgão internacional de direitos humanos, recebeu grande atenção no contexto político e acadêmico (COOK, 2013; KISMÖDI et al, 2013; OLIVEIRA; SCHRIMER, 2012).

O último "caso" a ser descrito é o de Claudia Silva Ferreira. Claudia tinha 38 anos quando foi baleada no Morro da Congonha, zona norte do Rio de Janeiro, onde vivia com seu marido e quatro filhos. No dia 16 de março de 2014, um domingo, ela saiu para comprar comida para sua família quando 
a PM iniciava uma operação. Claudia foi baleada e, segundo testemunhas, ainda com vida, foi colocada no porta-malas da viatura para ser levada ao hospital. Numa avenida de intensa movimentação, o porta-malas abriu e o corpo de Claudia foi arrastado por mais de 250 metros. A cena, registrada por um cinegrafista amador, alcançou enorme repercussão e no dia seguinte ao crime, a instituição de relações públicas da PM informou lamentar o ocorrido, afirmando que "a forma como a senhora Claudia foi socorrida é uma forma que [...] não toleramos. [...] Por essa razão, eles [os policiais envolvidos na ação] estão sendo autuados e [...] conduzidos à unidade prisional” (MACHADO, 2014, s/p). Assim como no massacre na escola Raul Brasil, em curtíssimo prazo, o representante do poder executivo, na época o governador Luiz Fernando Pezão, propôs acordo com os familiares de Claudia no que se refere ao pagamento de indenização com valor não divulgado, além de prestar assistência social aos familiares.

Através desses episódios de violações de direitos, apresento reflexões sobre o tema das indenizações no que se refere à relação entre vítimas e/ ou familiares de vítimas e gestores da administração pública brasileira. Com isso, de maneira específica, pretendo contribuir para o debate acadêmico e político em torno das indenizações enquanto práticas de direitos humanos cada vez mais frequentes, defendidas como práticas adequadas à reparação de direitos violados por um amplo e diversificado conjunto de agentes. Em termos teóricos mais amplos, as discussões aqui apresentadas podem ser interpretadas como uma contribuição para o debate sobre administração pública, principalmente por enfatizar as fronteiras porosas, maleáveis e contextuais entre o que se poderia considerar "Estado" e o que estaria fora de seu escopo, visto, até mesmo, como forças antagônicas a ele, como coletivos políticos, movimentos sociais etc. Como veremos, representantes do poder executivo ou de instituições que compõe a estrutura da administração pública, ou o "Estado" de maneira geral e abstrata, são pessoalizados como sendo, eles próprios, os perpetradores das violações, ao mesmo tempo em que se espera, por parte desses mesmos agentes, senso de justiça, compreensão e 
compaixão em relação ao "sofrimento" resultante da situação de violação sofrida, muitas vezes referida como "o pior momento de suas vidas".

Em termos metodológicos, apresento um enfoque etnográfico dos "casos" aqui descritos, o que quer dizer que, a partir de situações singulares, ressalto a recorrência de categorias, de práticas e de percepções dos sujeitos envolvidos com o objetivo de compreender aspectos gerais de um mesmo processo político do qual as situações singulares, ou seja, os “casos", são parte. Conforme argumentei, o que está sendo apresentado como material empírico neste artigo são situações heterogêneas que envolvem práticas de indenização que têm em comum, justamente, o fato de terem sido percebidas e categorizadas, por um amplo conjunto de agentes que envolve operadores do direito, gestores públicos, organizações internacionais, vítimas e/ou seus familiares, como situações de violações de direitos humanos. Dessa maneira, as particularidades dos "casos" não obliteram, apenas reforçam, o recorte aqui apresentado relativo a situações compreendidas como violações de direito passíveis de serem indenizadas em que vítimas e/ou seus familiares e representantes da administração pública brasileira estão envolvidos.

O artigo está dividido em três partes, além dessa introdução e das perspectivas finais. No primeiro tópico, "Reparar, compensar e indenizar", apresento um histórico possível das práticas e das políticas de indenização no Brasil, relacionando-as com o contexto internacional mais amplo. Mais do que dispor informações em ordem cronológica, o objetivo dessa seção é apontar para o processo por meio do qual práticas de indenização foram construídas e significadas como dimensão importante de políticas de direitos humanos e de justiça social. $\mathrm{Na}$ segunda parte, apresento reflexões sobre quais são os deslocamentos necessários, conduzidos tanto por vítimas e/ou seus familiares quanto por agentes públicos envolvidos nas políticas de reparação, para que uma quantia em dinheiro possa significar uma forma possível de reparar situações consideradas como "o pior momento de suas vidas", ou seja, sofrimentos frequentemente referidos como inesquecíveis, imensuráveis, irreparáveis. Por fim, nas perspectivas finais, teço considerações gerais sobre efeitos possíveis das práticas e das políticas de indenização no Brasil atual. 


\section{REPARAR, COMPENSAR, INDENIZAR}

Na obra Os Nuer (2008), de 1940, Evans-Pritchard, um antropólogo britânico interessado em compreender instituições políticas, apresenta uma descrição do modo de subsistência e das instituições políticas de um povo nilota. Uma dessas instituições é definida como "vendeta", um estado de coisas que decorre da infração da lei, o que dá lugar a um processo social e político que são os ressarcimentos, na descrição de Evans-Pritchard (2008), os Nuer são um povo briguento que se sente facilmente insultado. À semelhança da lista de Jorge Luis Borges, Evans-Pritchard enumera causas possíveis de uma briga:

Desentendimentos em relação a uma vaca, uma vaca ou cabra comer o sorgo de uma pessoa e esta bater naquela; um homem bater no filho pequeno de outro; adultério; direito sobre a água na estação da seca; direito sobre o pasto; um homem tomar emprestado algum objeto especialmente um ornamento de dança - sem pedir licença ao dono (EVANS-PRITCHARD, 2008, p. 162).

Um tipo específico de vendeta seriam os homicídios, e é a partir desses acontecimentos que o autor descreve, de forma detalhada, as negociações entre membros de tribos distintas quando "um homem mata o outro" (EVANS-PRITCHARD, 2008, p. 163). Quando ocorre um homicídio, escreve o autor, o assassino vai para a casa do "chefe da pele de leopardo" com o objetivo de se proteger de possíveis retaliações da família do morto e também para "limpar seu sangue" (EVANS-PRITCHARD, 2008, p. 163). Passado um período de reclusão do assassino sob a proteção do chefe (e, nesse período, a família do morto tenta atacá-lo para fins de vingança), o chefe inicia as negociações. Descreve o autor que o primeiro ato do chefe é verificar a quantidade de gado dos parentes do assassino e saber se eles estão dispostos a pagar a indenização. Em visita à família do morto, o chefe precisa insistir muito para que "aceitem o gado em troca da vida" (EVANS-PRITCHARD, 2008, p. 164), pois os parentes tendem a recusar a proposta e manter essa decisão por um período, apresentando suas versões do homicídio, enfatizando a qualidade do morto 
etc. Para o autor, no que se refere aos parentes do morto, "é ponto de honra ser obstinado" (EVANS-PRITCHARD, 2008, p. 164). Evans-Pritchard nota a existência de uma "cerimônia de reconciliação", mas infelizmente não a descreve. O objetivo dessa cerimônia e dos sacrifícios que decorrem do homicídio e o consequente processo de ressarcimento é "apaziguar o espírito e manter a honra dos vivos", o que significa que os parentes de ambos os lados devem ser purificados a fim de "livrar a aldeia da morte" (EVANS-PRITCHARD, 2008, p. 165).

A narrativa de Evans-Pritchard é envolvente, ela convence o leitor a respeito da singularidade do povo nilota em relação à sua organização política: sem estado, governo, leis, hierarquia, ou instituições como o exército e a polícia, mas ainda assim possuidores de um sistema político - uma "anarquia ordenada" (EVANS-PRITCHARD, 2008, p. 11) - fundamentado no sistema de linhagens, e a estrutura, no território. Arbitramento e conciliação, prática e objetivo decorrente de disputas que podem ocasionar a separação ou fusão de grupos, são descritos como uma especificidade Nuer, sem qualquer paralelo com sistemas políticos ocidentais. A descrição das formas de solução de homicídios, através do pagamento de uma certa quantidade de bois e vacas, chama a atenção pela possibilidade de equivalência entre coisas tão distintas: vidas, pessoas, propriedades, rebanhos. Aos olhos dos ocidentais, tais práticas poderiam ser consideradas exóticas, não fosse o contexto da década de 1970, em que emergiram os princípios da chamada justiça restaurativa, no âmbito da justiça de transição. Em países marcados por um passado de regimes políticos em que proliferaram conflitos, perseguições com saldo de mortes, torturas e desaparições forçadas, entre outras práticas autoritárias, foram pensadas estratégias com o objetivo de enfrentar e superar o passado. No caso brasileiro e de vários países latino-americanos, a ideia de justiça de transição associa-se à transição necessária entre o passado ditatorial e as perspectivas democráticas (AZEVEDO, 2016).

Segundo Caravellas (2009), a justiça restaurativa surge da crítica ao caráter extremamente punitivo, repressor e dissociativo da justiça penal. Apresenta uma forma de tratar o crime como "a ofensa de uma pessoa contra outra" e não como "a violação de uma norma prevista em código" 
(CARAVELLAS, 2009, p. 122). Nestes termos, a justiça restaurativa tem na reparação do dano causado à vítima e na reconstrução das relações humanas esgarçadas pela ofensa suas principais formas de atuação. Na justiça restaurativa os danos a serem reparados são de ordens variadas e múltiplas, podendo ser materiais, morais ou emocionais e a solução abrange reparação financeira, pedidos de desculpas e a adoção de medidas (institucionais) que impeçam a repetição do dano, violação ou conflito. Conforme Schuch (2006, p. 4-5) demonstra, no Brasil, os entusiastas da justiça restaurativa associam seu conjunto de práticas tanto a "modernas" normativas internacionais de proteção aos direitos humanos e propostas de desenvolvimento nacional, como também salientam sua origem "antropológica”, afirmando que a "justiça restaurativa” tem como inspiração os processos maoris de resolução de conflitos.

Seguramente, as práticas associadas à justiça restaurativa e sua busca pela paz social alcançaram grande visibilidade na década de 1990, durante a experiência dos Tribunais da Verdade e da Reconciliação realizados na África do Sul em função do apartheid. Para organismos internacionais como a Anistia Internacional e a Comissão Interamericana de Direitos Humanos, as políticas de reparação são consideradas como formas de reabilitação e reconciliação abrangentes e eficazes, não apenas pela concessão de indenizações, mas pela quebra do silêncio a respeito das atrocidades praticadas. Em 2003, a Anistia Internacional publicou uma nota na qual afirma que a reparação é um direito e, mais do que isso, uma "obrigação do Estado" quando ele é responsável ou corresponsável pela violação de direitos (BUFORD; MERWE, 2004).

No Brasil, as práticas e as políticas de indenização integram o campo dos direitos humanos e também remetem ao contexto dos anos de 1990. A Lei 9140/95 (BRASIL, 1995), que nasce como um Projeto de Lei do Executivo, é a primeira iniciativa pública que estipula a concessão de indenização em relação a danos imateriais. Através dela, foi previsto o pagamento de indenização para os cônjuges, companheiro ou companheira, descendentes, ascendentes e parentes colaterais de até quarto grau de pessoas mortas ou desaparecidas em razão de participação ou acusação de participação em atividades políticas no período 
de 2 de setembro de 1961 a 15 de agosto de 1979, período correspondente aos governos militares'. No texto da lei, afirma-se que a indenização possui fins reparatórios, mas esse não é o único elemento que aproxima o pagamento de uma quantia em dinheiro dos princípios da justiça restaurativa. Na justificativa que acompanha o texto da lei, afirma-se que a medida tem como propósito "resolver um assunto penoso na perspectiva de que as paixões devem ceder lugar a sentimentos edificadores" (BRASIL, 1995, p. 18).

Sob a gestão do Ministro da Justiça José Gregori, o Projeto de Lei do executivo foi encaminhado para três comissões: de Finanças e Tributação, de Constituição e Justiça, e de Direitos Humanos, indicando de maneira consistente o universo em torno do qual, no Brasil, foram formuladas as políticas e práticas a serem aplicadas quando o dano é compreendido como imaterial. No que se refere à definição do valor a ser pago, acorda-se $\mathrm{R} \$ 3.000,00$ para cada ano correspondente à expectativa de sobrevida do desaparecido, levando-se em consideração a idade na época do desaparecimento. Acrescenta-se que nenhuma indenização será inferior a $\mathrm{R} \$ 100.000,00$. Ao longo das 263 páginas que compõe o Dossiê do Projeto de Lei, não há rastros sobre os debates que chegaram na definição desses valores ou sobre quais teriam sido os parâmetros empregados.

O pagamento de indenização em decorrência de um dano imensurável como a perda de um/a companheiro/a pela perseguição política, o que pode ter sido precedido por torturas, prisões arbitrárias, anos de clandestinidade, separação familiar etc., abriu caminho para que outras situações fossem compreendidas como indenizáveis. São dois os elementos que possibilitaram esse movimento de ampliação no universo das indenizações: a percepção de que determinadas situações de violência e sofrimento tem causas sociais e políticas, e a percepção da responsabilidade (por ação direta ou omissão) do "Estado" através de seus agentes. Assim, chacinas cometidas por agentes da segurança pública, negligências médicas ocorridas em unidades de saúde,

\footnotetext{
Em 2004, foi revogado o artigo $1^{\circ}$ da Lei 9140/95, em que constava a definição do período dos casos que seriam considerados para fins de indenização, passando a apresentar a data de " 5 de outubro de 1988 " (BRASIL, 1995) como data término do período de abrangência dos efeitos da lei. Essa data corresponde à promulgação da Constituição Federal, o que pode ser compreendido como uma tentativa de marcar, efetiva e simbolicamente, a distinção entre o período regido por uma "Constituição Cidadã” e os anos anteriores, em que houve perseguição política com emprego de torturas, desaparecimento forçado, crimes de mortes, estupro e outros.
} 
atentados ocorridos em escolas do estado, como também crimes em que a polícia ou a justiça tardaram a tomar medidas cabíveis, tornam-se ações de responsabilidades da administração pública brasileira às quais, enquanto fato consumado, só é possível reparar, compensar, indenizar.

Aquilo que, na descrição de Evans-Pritchard (2008) a respeito dos Nuer, parecia ser impensável, ou seja, a possibilidade de equivalência entre a vida, tomada como algo acima de todos os valores, e uma quantia de gado tomada como unidade econômica, encontra possibilidades interessantes de comparação com as ações contemporâneas de indenização. Entre os Nuer, como também nos "casos" a serem aqui tratados, trata-se de uma prática política que assume os termos de uma "negociação" intermediada por um "árbitro", mesmo que não sejam claros e públicos os termos dessa negociação, ou mesmo que ela não se estabeleça entre iguais, mas em contextos de marcada assimetria. Entre os Nuer, como vimos, o chefe da pele de leopardo, levando em conta as condições econômicas daqueles que devem pagar uma indenização, estipula um valor, produz uma equivalência que, por sua vez, será objeto de contestação da família do morto que afirma e reafirma, ao longo de todo o processo, a singularidade da vítima, o que quer dizer a impossibilidade de qualquer equivalência.

Em relação aos "casos" aqui analisados, nos dois que foram objeto de denúncia internacional houve divergências em relação ao valor da indenização a ser paga, o que fez com que a negociação se estendesse no tempo. Em todos os outros "casos", propostos pelos familiares das vítimas ou pelo representante do poder executivo, os valores foram acordados, o que não quer dizer que não tenham havido outras formas de "mostrar-se obstinado", conforme as palavras de Evans-Pritchard (2008, p. 167), no que se refere a demonstrar o valor do familiar morto. Em todos os "casos", contudo, as divergências não inviabilizam o acordo, nem mudam seus termos.

Entre os Nuer (EVANS-PRITCHARD, 2008), o que parece estar em jogo na definição da indenização é a capacidade de pagamento do devedor. Nas indenizações em "casos" de violação de direitos humanos aqui analisados, o que se mostra decisivo são as características da vítima. O sigilo a respeito dos valores das indenizações, em alguns casos, impede que se conheçam 
as quantias, mas é acompanhado da informação de que os valores concedidos "estão dentro dos padrões praticados em casos similares" seja em discursos públicos proferidos por autoridades, seja em notas oficiais emitidas pelos setores de comunicação dos governos envolvidos. Situações similares, pelo que se pode depreender do universo das indenizações aqui analisado, são outras violações de direito cometidas em favelas, como resultado do poder bélico das forças de segurança, ou ocorridas em serviços públicos acessados por pessoas pobres, ou efeitos de situações em que omissões do sistema de justiça produziram grandes impactos na garantia de direitos de pessoas já vitimadas por outras situações. Nesse sentido, a despeito das indenizações serem práticas de direitos humanos que, como tais, não se direcionam a nenhum sujeito específico, mas potencialmente a todos, aqueles que vem sendo indenizados por violação de direitos são as vítimas preferenciais de serviços públicos de má orientação, de baixa qualidade ou insuficientes, o que apenas ilumina a questão complexa em torno dos valores pagos por cada vida.

\section{REPARANDO DORES E SOFRIMENTOS}

Dona Carolina é mãe de Maurício, que desapareceu em Altamira, no Pará, em 1993, período em que os crimes de emasculação aterrorizavam crianças e adultos, principalmente pelo fato de restarem sem solução por parte dos setores competentes. Como o corpo de Maurício nunca foi encontrado, apesar da intensa repercussão alcançada e, apesar de "citado" no processo judicial aberto em nome de outras crianças (sobreviventes e mortas, todas vítimas de lesão no órgão sexual), esse "caso" não foi objeto de atuação da polícia ou da justiça. Anos depois de realizado o julgamento do "caso", Dona Carolina me concedeu entrevista, comentando sobre o recebimento de uma pensão paga pelo governo do estado:

"Ah, Carolina tá ganhando um salário". Eu digo: "um salário não paga uma sentada nossa numa cadeira daquela do Tribunal”. Por causa do 
sofrimento que causou a nós. Sabe o que é, mana, você perder um filho que era um pedaço de você e você ter que de cinco em cinco dias, de oito em oito dias ter que sentar na frente de uma multidão e contar pra aquelas pessoas tudo o que aconteceu?!

O "salário" recebido por Dona Carolina foi resultado de uma ação cível apresentada pela mesma organização não governamental (ONG) que havia assistido os familiares desde quando os crimes contra meninos ocorreram em Altamira, até o julgamento ocorrido em 2003. O Centro de Defesa da Criança e do Adolescente (Cedeca-Emaús), por intermédio da advogada e diretora da instituição, deu entrada em uma "ação indenizatória" incluindo os familiares de meninos sobreviventes, mortos ou desaparecidos no "episódio denominado meninos emasculados de Altamira, ocorrido no período de 1989 a 1993", conforme constou no texto da Lei $\mathrm{n}^{\circ} 7.185 / 2008$, aprovada pela Assembleia Legislativa do Estado do Pará (PARÁ, 2008). No total, dez pessoas, sendo oito mães, uma irmã e um pai são beneficiários das pensões. Todos são integrantes do Comitê em Defesa da Vida da Criança Altamirense, a instituição formada pelos familiares das vítimas, ainda na década de 1990, para "lutar por justiça" em relação ao "caso dos meninos", como se referem.

Sem que eu estimulasse Dona Carolina a tratar especificamente sobre seu "salário", ela nos leva ao universo das tensões em torno do recebimento de uma indenização, ou mais especificamente das tensões decorrentes do recebimento de uma quantia em dinheiro em face de dores e sofrimentos iniciados prela perda do filho e são revividos a cada vez em que se faz necessário falar sobre o assunto diante de uma plateia numerosa e desconhecida. No universo dos familiares de vítimas indenizados, os mesmos incômodos expressos por Dona Carolina se repetem, como podemos observar também na etnografia de Tello (2003) a respeito da concessão de indenizações aos familiares de desaparecidos políticos durante a ditadura na Argentina. Segundo discute a autora (TELLO, 2003, p. 57), enquanto algumas das associações de familiares de vítimas manifestaram contrariedade em relação às indenizações, entendendo que o "dinheiro" não seria o instrumento para reparar algo que só poderia ser reparado com “justiça”, outros afirmam que a indenização representa o reconhecimento da culpa pelo que podia 
ser evitado e agora não pode ser reparado. Como a autora demonstra, o dinheiro, percebido em sua incompatibilidade com o sofrimento causado pelo desaparecimento, tortura e morte de um familiar, foi utilizado por alguns beneficiários como uma estratégia política. Considero como um processo de "conversão moral do dinheiro" os esforços que as vítimas e/ou seus familiares fazem no sentido de transformar as indenizações em uma forma possível de reparar o que é considerado imensurável e irreparável.

Nos "casos" expostos pela pesquisa, as indenizações não surgem espontaneamente como demanda das vítimas ou de seus familiares, mas como parte das ações oferecidas por instituições de direitos humanos que se tornam responsáveis pela representação, assistência ou atendimento das vítimas e/ou familiares; ou em "casos" de grande repercussão como o massacre na escola Raul Brasil ou o homicídio de Claudia Ferreira, como proposta de setores públicos responsáveis de maneira direta ou indireta pela violação sofrida. Isso não significa, no entanto, que as vítimas e/ou seus familiares não desejem receber uma indenização, ou que não a considerem como parte de seus direitos, mas passar a recebê-la, sem dúvida, é fruto de um processo político que se inicia após terem seus direitos violados e estarem em contato com instituições governamentais ou não-governamentais.

No que se refere aos familiares de vítimas, é bastante perceptível esse movimento, sendo possível afirmar que o processo de "conversão moral do dinheiro" passa pela significação das indenizações não como reparação à perda de um filho ou familiar, posto que isso é irreversível e irreparável, mas como resultado de anos de "luta". A fala da mãe de Alyne Pimentel, na cerimônia de reparação indenizatória organizada pela Secretaria de Direitos Humanos da Presidência da República, é explícita nesse sentido:

E esse reparo que tá sendo agora é pouco por muito que ainda tem que vir por aí. Porque foi um dia, um minuto que tirou a vida da minha filha, mas esse reparo, que tá começando agora, levou doze anos. (CASO..., 2014, 51:22)

Para além do processo político por meio do qual as vítimas e/ou seus familiares compreendem as indenizações como direito, existe uma dimensão 
fundamental nas indenizações que é o reconhecimento da responsabilidade do "Estado" que legitima anos de luta (em alguns casos), e também produz uma narrativa sobre os fatos e sobre a própria posição ou identidade de "vítima" e/ou "familiar de vítima" que podem ter sido contestados ao longo de muitos anos, por meio de falas públicas de autoridades, recursos judiciais, entre outros. Essa dimensão do reconhecimento conferido via indenização concorda com as expectativas das vítimas e/ou seus familiares envolvidos na "luta por justiça", inclusive nos "casos" em que não houve julgamento dos crimes, não havendo, portanto, responsabilização penal dos agentes violadores. Assim, quando o "Estado" paga uma indenização, isso significa em termos políticos o reconhecimento público da responsabilidade de suas instituições na violação de direitos, o que é ainda mais significativo em "casos" nos quais durante anos negou-se a responsabilidade. No "caso Alyne Pimentel", por exemplo, que tem como desfecho a responsabilização do Brasil pelo Comitê da Cedaw, a morte da vítima é compreendida como uma "morte materna evitável" e, mais do que isso, "um exemplo perverso do que o racismo institucional produz no sistema de saúde do Brasil', conforme a fala de Luiza Helena de Bairros, então ministra da Secretaria de Políticas de Promoção da Igualdade Racial. (CASO..., 2014).

Ser beneficiário de uma indenização transforma identidades e ressignifica trajetórias. Assim, no que se refere às vítimas da repressão política, aqueles que eram chamados de "terroristas" e considerados como "inimigos da pátria" recebem a categoria de "perseguidos políticos". Em relação à chacina da Nova Brasília, a transformação foi também bastante significativa no que se refere aos aspectos morais envolvidos: de "supostas vítimas" ou "traficantes" para "vítimas da violência policial". Para Dona Carolina, que havia sido acusada pelas autoridades policiais de negligência, o reconhecimento concedido via indenização reformula a responsabilidade do crime: não seria ela, uma mãe pobre, a responsável pelo desaparecimento do seu filho, mas sim as autoridades omissas diante dos crimes que vitimavam cada vez mais meninos em Altamira. Nesse "caso", a indenização também cumpre um importante papel simbólico e afetivo, pois é compreendida como o resultado de um esforço feito pela memória do filho. 
A ideia de que as medidas de reparação, entre as quais as indenizações, pouco podem reparar em face da incomensurabilidade do sofrimento causado pela violação faz parte, também, das narrativas de gestores públicos envolvidos nas políticas de reparação. De fato, a compreensão de que violações de direito são irreparáveis está presente em documentos e análises da Organização das Nações Unidas ${ }^{10}$, o que, contudo, não enfraquece o tema das indenizações. Ao contrário, reafirmam a indenização como um direito das vítimas e obrigação do Estado, devendo ser fornecida em razão de "qualquer dano economicamente qualificável", onde se incluem "dor, sofrimento e distúrbios emocionais" (VAN BOVEN, 2010, p. 422). Na cerimônia de reparação indenizatória do "Caso Alyne", as palavras finais e emocionadas de Eleonora Menicucci, então ministra da Secretaria de Políticas para as Mulheres da Presidência da República, posicionam o sofrimento como propriedade da mãe de Alyne, cabendo ao governo federal, a responsabilidade de reparação:

O sofrimento da senhora... é muito doloroso para nós dizermos que o sofrimento da senhora foi marcado com sangue uma história e é com essa história que nós temos compromisso. Mas o sofrimento é da senhora. Esse sofrimento ninguém lhe tira, só podemos ser solidárias a ele e dizermos que essa ação aqui hoje é o compromisso do Governo Federal. (CASO..., 2014, 1:22: 47).

Dessa maneira, embora os fundamentos em torno das indenizações consistam na percepção de que dificuldades financeiras podem ser originadas ou agravadas pela violação, sendo obrigação do poder público reparar isso, a dimensão da dor e do sofrimento é aspecto central nas práticas de indenização, como se pode perceber a partir da fala de uma autoridade durante cerimônia, ou na fixidez dos princípios e recomendações constantes em instrumentos internacionais de direitos humanos. Afirmando que o sofrimento não

\footnotetext{
${ }_{10}$ Destaco o seguinte trecho do Relatório Final apresentado por Theo Van Boven (2010, p. 416): “É óbvio que as violações graves aos direitos humanos e liberdades fundamentais, especialmente quando cometidos em escala massiva, são por sua natureza irreparáveis. Nesses casos, não existe qualquer remédio ou reparação proporcional ao dano infligido às vítimas. É, portanto, norma imperativa de justiça que a responsabilidade dos perpetradores seja claramente estabelecida e que os direitos das vítimas sejam suportados ao máximo".
} 
pode ser mensurado, nem reparado, nem comparado, valores são propostos, às vezes regateados, e modalidades de pagamento são acertadas. Nada disso, contudo, é feito sem a reiteração de fórmulas que ao mesmo tempo constroem a dor e o sofrimento como dimensões individuais e únicas e, também, como aspecto estruturante de políticas e práticas de direitos humanos.

\section{PERSPECTIVAS FINAIS}

Nos últimos anos, vem ganhando a atenção de análises socioantropológicas a importância da categoria "vítima" para compreensão do cenário político contemporâneo, não só no Brasil, como mostram os estudos de Sarti (2011, 2014), Vecchioli e Martinelli Leal (2017) e Vecchioli (2018), mas também em outros países da América Latina (GATTI; MARTÍNEZ, 2017; JIMENO, 2010; ZENOBI, 2014, 2019) e do mundo (FASSIN; RECHTMAN, 2009; WIEWIORKA, 2003). A crescente importância dos movimentos sociais e dos coletivos políticos desde a redemocratização do país é sem dúvida parte importante na legitimidade conferida a sujeitos políticos que deixam de ser exclusivamente representantes de causas e de coletividades durante as décadas de 1980 e 1990, para serem, dos anos 2000 em diante, sujeitos que falam de si em primeira pessoa, apresentando sua experiência, seus sofrimentos, suas dores, como base para a formulação de denúncias cuja expectativa é que se transformem em medidas (décadas de 1980 e 1990) a fim de evitar a repetição daquele dano. O protagonismo alcançado por grupos de familiares e, especificamente, de "mães de vítimas" representa, seguramente, uma transformação social e política recente no sentido da legitimidade conferida a certos sujeitos políticos em nome de vínculos afetivos (e de sangue) tomados como primários (CATELA, 2001; FREITAS, 2002; LEITE, 2004) e legitima sentimentos como a dor e o sofrimento enquanto experiências constitutivas do sujeito e da reivindicação de direitos.

A identidade política de "vítima", "familiar de vítima", ou "mãe de vítima" evidencia a linguagem do sentimento e do sofrimento que foi incorporada 
ao cenário político de maneira vigorosa. Assim, as políticas de reparação que visam, ao mesmo tempo, oferecer um tratamento para a violação de direitos que alcance as dimensões individuais, afetivas e estruturais, são respostas condizentes à percepção do sujeito político a partir de suas experiências, individuais e sociais, de dor e sofrimento. Por meio de medidas como as indenizações, o reconhecimento da responsabilidade pela falha ou omissão de serviços públicos e o compromisso com a formulação de políticas públicas que pretendem evitar a repetição da violação, é possível notar a presença de ações voltadas às dimensões individual e social de situações como as de violações de direito. Isso também é expresso pela preocupação mais ampla, que fundamenta as políticas de reparação como um todo, em torno da "reconciliação dos laços sociais", entre aqueles que tiveram seus direitos violados, os setores responsáveis pela violação e a "sociedade" que vivenciou tais violações.

Chama a atenção que esse processo de reconhecimento de identidades políticas fundamentado por experiências de dor e de sofrimento se faça em relação à figura do "Estado", seja em sua dimensão propositalmente abstrata [e aqui, tomo as proposições de Abrams (1988) como inspiração], seja a partir de setores ou personalidades específicas ("a PM do Estado do Rio de Janeiro", "o governador Luiz Fernando Pezão"), ou ainda, de situações com graus distintos de permanência ("a política genocida do governo estadual", "o racismo estrutural" de determinados órgãos públicos etc.). Tanto nos "casos" em que ocorre o reconhecimento da responsabilidade nas violações por parte de setores específicos da administração pública brasileira como em outros em que, quase sempre via denúncia a órgãos internacionais de direitos humanos, o responsabilizado é "o Brasil", a dimensão do reconhecimento se faz notável no discurso das vítimas e/ou de seus familiares.

Por meio de processos distintos como a concessão das indenizações pelo massacre na escola Raul Brasil, o caso dos meninos emasculados de Altamira, ou a chacina da Nova Brasília, são órgãos públicos os que se tornam responsáveis pela dimensão do reconhecimento da violação de direitos, cuja importância é ressaltada pelas vítimas e/ou seus familiares em suas narrativas. No cenário das políticas de reparação de maneira mais ampla, 
é possível afirmar que as indenizações, em particular, são medidas mínimas e ao mesmo tempo suficientes para garantir essa dimensão do reconhecimento.

Ao afirmar que as indenizações são medidas mínimas no contexto das políticas de reparação, proponho que mesmo quando desacompanhadas de outras práticas tidas, inclusive, como estruturantes dessas políticas, as indenizações são consideradas como ações de direitos humanos e de justiça social. Assim, enquanto as violações que foram objetos de denúncia internacional tendem a resultar na proposição de um amplo conjunto de medidas, das quais as indenizações são apenas uma parte, o "caso Claudia Ferreira", aqui tratado, resultou apenas na concessão de indenizações, embora tenha sido divulgado que os familiares da vítima receberiam "assistência social". De fato, os resultados apresentados pela pesquisa permitem observar que quando a violação de direitos foi praticada por agentes da segurança pública, o pagamento de uma quantia em dinheiro torna-se quase sempre a única ação provida pela administração pública. Ainda assim, como dissemos, a indenização paga não deixa de ser compreendida enquanto medida de reparação, seja pelos agentes públicos à frente da proposta, seja pelas vítimas e/ou seus familiares, sendo considerada, portanto, uma medida de direitos humanos e de justiça social.

Ainda no que se refere ao "caso Claudia Ferreira”, os agentes da lei responsáveis por terem arrastado seu corpo em via pública, encontram-se na ativa e, segundo a mídia, já se envolveram em outras oito mortes durante operações policiais (SOARES, 2018). Em entrevista à imprensa, um dos irmãos de Claudia - não incluído na indenização paga aos familiares - afirmou que "o caso vai dar em pizza, infelizmente" (SOARES, 2016, s/p.). Pela análise dos casos de indenização que acompanhamos ao longo da pesquisa, é certo que quando as violações envolvem violência policial são grandes os desafios em torno do reconhecimento da responsabilidade dos órgãos públicos competentes e da adoção de reformas. Não por acaso, as indenizações que resultam desse tipo de violações costumam ter o formato de acordos extra-judiciais em que não há compromissos firmados para além da indenização: a tramitação é rápida, não transparente e pode apresentar cláusulas impeditivas de ações judiciais futuras (como no massacre da escola Raul Brasil). A atmosfera de "eficiência" e "celeridade" - que se apresenta até mesmo 
como uma prática de respeito associada aos direitos humanos - tem o efeito prático de tirar o tema de circulação, uma espécie de "encerramento do caso" que, sem dúvida, se favorece da condição de vulnerabilidade e hipossuficiência das vítimas e seus familiares: pessoas comuns, negras, pobres, moradoras de espaços periféricos. Em certos casos, principalmente diante da disfuncionalidade do programa de proteção às testemunhas, aceitar uma indenização, sobretudo se concedida de maneira rápida, pode fazer a diferença entre sair do espaço da favela, e manter-se vivo, ou estar sujeito a novas investidas das mesmas forças policiais, e morrer.

Em todos os "casos" analisados, independente de terem sido tema de denúncia internacional, a administração pública brasileira é objeto de um processo de personificação em que se torna não apenas possível como desejável a transformação de governos e setores de serviços públicos em "pessoas" capazes de se responsabilizar e de se desculpar. Assim, o "governador" passa a responder pelos setores estaduais de segurança pública e/ou de educação, como no "caso" da escola Raul Brasil; o "Brasil" passa a responder como violador de direitos reprodutivos das mulheres, como no "caso Alyne Pimentel". Assumindo a figura de uma entidade personalizada, é possível alcançar práticas como o se desculpar e se responsabilizar. A ação indenizatória, em termos simbólicos, dramatiza a relação de dívida, monetária e moral, entre o "Estado" ou outra figura pessoalizada que esteja envolvida no processo de reparação, e a vítima e/ou seu representante.

O presente artigo não teve como objetivo analisar a efetividade das políticas de indenização ou de reparação no Brasil contemporâneo, não se tratando, portanto, de um diagnóstico sobre esse tipo de ações. No entanto, gostaria de concluir apontando que apesar das indenizações serem medidas de reparação consideradas positivas e necessárias por um amplo e diversificado conjunto de agentes, diante da capacidade do tema acionar ideais de direitos humanos e de justiça social, é preciso acompanhar com atenção os efeitos que as indenizações produzem no campo das políticas sociais mais amplas, marcadas por níveis distintos de afinação e permeabilidade aos princípios e práticas de direitos humanos. Nesse cenário, torna-se importante analisar as 
formas pelas quais setores ou serviços públicos operacionalizam as indenizações para evitar que práticas consideradas eficazes no processo de reparação produzam efeitos dissociativos ou descomprometidos com medidas que impeçam a repetição da violação.

\section{REFERÊNCIAS BIBLIOGRÁFICAS}

1. ABRAMS, Phillip. Notes on the Difficulty of Studying the State (1977). Journal of Historical Sociology, Hoboken, v. 1, n. 1, p. 58-89, 1988.

2. AZEVEDO, Desirée de Lemos. "A única luta que se perde é aquela que se abandona": etnografia entre familiares de mortos e desaparecidos políticos no Brasil. 2016. Tese (Doutorado em Antropologia Social) - Universidade Estadual de Campinas, Campinas, 2016.

3. BASILIO, Ana Luiza. Massacre de Suzano é o oitavo em escolas do Brasil desde 2002. Carta Capital, São Paulo, 13 mar 2019. Sociedade. Disponível em: http://bit.ly/39Lf3pA. Acesso em: 18 fev. 2020.

4. BOLTANSKI, Luc; DARRÉ, Yann; SCHLITZ, Marie-Ange. La dénonciation. Actes de La Recherche en Sciences Sociales, Paris, v. 51, p. 3-40, 1984.

5. BRASIL. Lei no 9140 de 4 de dezembro de 1995 . Reconhece como mortas pessoas desaparecidas em razão de participação, ou acusação de participação, em atividades políticas, no período de 2 de setembro de 1961 a 15 de agosto de 1979, e dá outras providências. Diário Oficial da União. Brasília, DF, p. 19985, 5 dez. 1995. Disponível em: http://bit.ly/38mE6z3. Acesso em 24 jun. 2019.

6. BUFORD, Warren; VAN DER MERWE, Hugo. Reparations in Southern Africa. Cahiers d'études Africaines, Paris, n. 173-174, p. 266-322, 2004. Disponível em: http://bit.ly/2ORnasO. Acesso em: 12 mar. 2008.

7. CARAVELLAS, Elaine. Justiça Restaurativa. In: LIVIANU, Roberto (org.) Justiça, cidadania e democracia. Rio de Janeiro: Centro Eldstein de Pesquisa Social, 2009. p. $120-131$.

8. CASO Alyne Silva Pimentel Teixeira. Secretaria de Direitos Humanos da Presidência da República. Rio de Janeiro: disponibilizado pela Secretaria de Políticas para as Mulheres da Presidência da República, abr. 2014. Disponível em: http://bit.ly/2OSejHn. Acesso em: 9 jun. 2019.

9. CATELA, Ludmila da Silva. Situação-limite e memória: a reconstrução do mundo dos familiares de desaparecidos na Argentina. São Paulo: Anpocs, 2001. 
10. CLAVERIE, Elizabeth. La naissance d'une forme politique: l'affaire du Chevalier de La Barre. In: ROUSSIN, Phillipe. (org.). Critique et Affaires de Blasphème à l'Époque des Lumières. Paris: Honoré Champion, 1998. p. 185-260.

11. COOK, Rebecca. Human rights and maternal health: exploring the effectiveness of the Alyne decision. Journal of Law, Medicine \& Ethics, Boston, v. 41, n. 1, p. 103-123, 2013.

12. EVANS-PRITCHARD, Edward Evan. Os Nuer: uma descrição dos modos de subsistência e instituições políticas de um povo nilota. São Paulo: Perspectiva, 2008.

13. FASSIN, Didier; RECHTMAN, Richard. The empire of trauma: an inquiry into the condition of victimhood. Princeton: Princeton University Press, 2009.

14. FREITAS, Rita de Cássia. Em nome dos filhos, a formação de redes de solidariedades: algumas reflexões a partir do caso Acari. Serviço Social e Sociedade, São Paulo, ano XXIII, n. 71, p. 80-101, 2002.

15. GATTI, Gabriel; MARTÍNEZ, María. El ciudadano-víctima. Notas para iniciar un debate. Revista de Estudios Sociales, Bogotá, v. 59, p. 8-13, jan. 2017.

16. JIMENO, Myriam. Emoções e Política: a vítima e a construção de comunidades emocionais. Mana, Rio de Janeiro, v. 16, n. 1, p. 99-121, 2010.

17. KISMÖDI, Eszter et al. A responsabilidade do campo dos direitos humanos com a morte materna e o fracasso em oferecer aborto legal e seguro: o significado de duas decisões inovadoras do CEDAW. Questões de Saúde Reprodutiva, Recife, ano 7, n. 6, p. 109-118, jul. 2013.

18. LACERDA, Lidia Neira Alves. "Vocês fazem isso porque tem medo de nos ouvir": análise dos discursos do Estado quanto aos direitos indígenas diante da usina Belo Monte. 2017. Dissertação (Mestrado em Antropologia Social) - Universidade Federal de Goiás, Goiânia, 2017.

19. LACERDA, Paula. "O caso dos meninos emasculados de Altamira": polícia, justiça e movimento social. 2012. Tese (Doutorado em Antropologia Social) Universidade Federal do Rio de Janeiro. Rio de Janeiro, 2012.

20. LACERDA, Paula. Meninos de Altamira: violência, "luta" política e administração pública. Rio de Janeiro: Garamond, 2014.

21. LEITE, Márcia. As mães em movimento. In: LEITE, Márcia; BIRMAN, Patrícia. (org.). Um mural para a dor: movimentos cívico-religiosos por justiça e paz. Porto Alegre: Ed. UFRGS, 2004. p. 141-190.

22. LOURENÇO, Fernanda. Governo do Estado divulga critérios para indenizações a vítimas do massacre na Escola Raul Brasil. G1, Mogi das Cruzes, 08 abr. 2019. Disponível em: https://glo.bo/2Hk3j10. Acesso em: 5 jun. 2019. 
23. 23. MACHADO, Mariucha. Mulher arrastada temia que filhos fossem confundidos com traficantes. G1, Rio de Janeiro, 17 abr. 2014. Disponível em: https://glo. bo/3bTQGHY. Acesso em: 18 fev. 2020.

24. OlIVEIRA, Aline Albuquerque Sant'Anna de; SCHIRMER, Júlia Barros. Caso Alyne Pimentel: uma análise à luz da abordagem baseada em direitos humanos. Revista do Instituto Brasileiro de Direitos Humanos, [s. l.], n. 12, p. 11-22, 2012.

25. PARÁ. Lei no 7.183 de 16 de junho de 2008. Dispõe sobre a concessão de Pensão Especial a Rosa Maria da Silva Pessoa, genitora de Jaenes da Silva Pessoa, vítima do episódio denominado "Meninos Emasculados de Altamira", ocorrido no período de 1989 a 1993. Diário Oficial do Estado do Pará, Belém, p. 6, 18 jun. 2008. Disponível em: http://bit.ly/2uwjlCr. Acesso em: 23 jul. 2019.

26. REALENGO, Janaúba e outros: episódios de ataques em escolas no Brasil. G1, Mogi das Cruzes, 13 mar. 2019. Disponível em: https://glo.bo/3bLn1kt. Acesso em: 18 fev. 2020.

27. REIS, Roberta Aguiar Cerri. Nós, os outros e os "parentes": política e povos indígenas no contexto de implantação da hidrelétrica de Belo Monte. 2015. Dissertação (Mestrado em Antropologia) - Universidade de Brasília, Brasília, DF, 2015.

28. SÃO PAULO. Decreto $n^{\circ} 64.145$ de 14 de março de 2019. Autoriza o pagamento de indenização às vítimas da tragédia ocorrida em 13 de março do corrente na Escola Estadual Professor Raul Brasil, no Município de Suzano, Estado de São Paulo, institui Comissão Executiva e dá providências correlatas. Diário Oficial do Estado de São Paulo, São Paulo, Executivo, Caderno 1, ano 129, n. 50, p. 1, 15 mar. 2019.

29. SÃO PAULO. Deliberação da Comissão Executiva, de 5-4-2019. Decreto 64.145 de 14-03-2019. Diário Oficial do Estado de São Paulo, São Paulo, Executivo, Seção 1, ano 129, n. 66, p. 146, 06 abr. 2019.

30. SARTI, Cynthia. A vítima como figura contemporânea. Caderno CRH, Salvador v. 24 , n. 61 , p. 51-61, 2011

31. SARTI, Cynthia. A construção de figuras da violência: a vítima, a testemunha. Horizontes Antropológicos, Porto Alegre, v. 20, n. 42, p. 77-105, 2014.

32. SCHUCH, Patrice. Direitos e afetos: análise etnográfica da "justiça restaurativa" no Brasil. Antropologia y Derecho, Misiones v. 7, p. 10-18, 2009. Disponível em: http://bit.ly/2vwqS3Z. Acesso em: 18 jul. 2019.

33. SIGAUD, Lygia. Efeitos sociais de grandes projetos hidroelétricos: as barragens de Sobradinho e Machadinho. Rio de Janeiro: PPGAS/MN/UFRJ, 1986. (Coleção Comunicações PPGAS, n. 9). 
34. SIGAUD, Lygia. Crença, descrença e interesses: por uma sociologia das condutas face ao deslocamento compulsório. In: ROSA, Luiz P.; SIGAUD, Lygia. LA ROVERE, Emílio Lèbre (org.). Estado, energia elétrica e meio ambiente: o caso das grandes barragens. Rio de Janeiro: Coppe, 1995. p. 162-184.

35. SOARES, Rafael. Dois anos após a morte de Claudia, arrastada por viatura, PMs não foram julgados. Extra, Rio de Janeiro, 16 mar. 2016. Disponível em: https://glo.bo/2ON1yxJ. Acesso em: 22 set. 2019.

36. SOARES, Rafael. PMs acusados pela morte de Claudia, arrastada por viatura, se envolveram em oito homicídios desde 2014. Extra, Rio de Janeiro, 16 mar. 2018. Disponível em: https://glo.bo/2UMwzFy. Acesso em: 22 set. 2019.

37. SOUZA, Sue Ellen Bispo de. Chacina de Nova Brasília: violência, sofrimento e reparação às vítimas e familiares. 2018. Dissertação (Mestrado em Ciências Sociais) - Universidade do Estado do Rio de Janeiro, Rio de Janeiro, 2018.

38. SOUZA LIMA, Antonio Carlos de. Sobre gestar e gerir a desigualdade: pontos de investigação e diálogo. In: SOUZA LIMA, Antonio Carlos de (org.). Gestar e Gerir: estudos para uma antropologia da administração pública no Brasil. Rio de Janeiro: Relume-Dumará, 2002. p. 11-22.

39. TEIXEIRA, Carla da Costa; SOUZA LIMA, Antonio Carlos de. A antropologia da administração e da governança no Brasil: área temática ou ponto de dispersão? In: DUARTE, Luís Fernando Dias (org.). Horizontes das ciências sociais no Brasil: antropologia. São Paulo: Anpocs, 2010. p. 51-95.

40. TELLO, Eva. La fuerza de la cosa dada: derechos humanos, política y moral en las 'indemnizaciones' a las víctimas del terrorismo de Estado en Argentina. In: KANT DE LIMA, Roberto (org.). Antropologia e Direitos Humanos. Niterói: Eduff, 2003. p. 37-74. (v. 2. Série Antropologia e Ciência Política, v. 33).

41. VAN BOVEN, Theo. Estudo sobre o direito de restituição, indenização e reabilitação de vítimas de violações graves aos direitos humanos e liberdades fundamentais: relatório final apresentado por Theo Van Boven, Relator Especial. Comitê de Direitos Humanos das Organizações das Nações Unidas. Anistia Política e Justiça de Transição, Brasília, DF, n. 3, p. 354-425, 2010.

42. VECCHIOLI, Virginia. Deserving victimhood: kinship, emotions and morality in contemporary politics. Vibrant, Brasília, DF, v. 15, n. 3, p. 1-22, 2018.

43. VECCHIOLI, Virginia; MARTINELLI LEAL, Eduardo. El activismo de las víctimas en contextos represivos y democráticos. Papeles del CEIC, Leioa, v. 1, p. 1-11, 2017.

44. VIEIRA, Flavia do Amaral. Direitos humanos e desenvolvimento na Amazônia: Belo Monte na comissão interamericana de direitos humanos. 2015. Dissertação (Mestrado em Direito) - Universidade Federal de Santa Catarina, Florianópolis, 2015. 
45. VILAÇA, Luiz. Costuras, deslocamentos e bricolagens: a atuação de procuradores do Ministério Público Federal no caso de Belo Monte. 2017. Dissertação (Mestrado em Ciência Política) - Universidade de Brasília, Brasília, DF, 2017.

46. WIEVIORKA, Michel. Lémergence des victimes. Sphero publica, Murcia, n. 3, p. 19-38, 2003.

47. ZENOBI, Diego. Familia, Política y Emociones: Las víctimas de Cromañón entre el movimiento y el Estado. Buenos Aires: Antropofagia, 2014.

48. ZENOBI, Diego. After the fire. Emotions, trauma and political mobilization in contemporary Argentina. In: MATERIALITIES AND EMOTIONS IN TIMES OF DISASTERS: AN ANTHROPOLOGICAL PERSPECTIVE, 2019, Paris. Anais eletrônicos [...]. Paris: Centre de Recherches Internationales, 2019. Disponível em: http://bit.ly/39AgXcK. Acesso em: 19 jul. 2019. 